\title{
Evidence of stock connectivity, hybridization and misidentification in white anglerfish support the need for adopting a genetics-informed fisheries management approach
}

\author{
Imanol Aguirre-Sarabia ${ }^{1}$, Natalia Díaz-Arce ${ }^{1}$, Iker Pereda-Agirre ${ }^{1}$, Iñaki Mendibil ${ }^{1}$, \\ Agurtzane Urtizberea ${ }^{1}$, Hans D. Gerritsen ${ }^{2}$, Finlay Burns ${ }^{3}$, Ian Holmes ${ }^{4}$, Jorge Landa ${ }^{5}$, \\ Ilaria Coscia ${ }^{6}$, Iñaki Quinconces ${ }^{1}$, Marina Santurtún ${ }^{1}$, Antonella Zanzi ${ }^{7}$, Jann T. \\ Martinsohn7, Naiara Rodríguez-Ezpeleta ${ }^{1, *}$ \\ ${ }^{1}$ AZTI, Marine Research, Basque Research and Technology Alliance (BRTA), Bizkaia, Spain \\ ${ }^{2}$ Fisheries Ecosystems Advisory Services, Marine Institute, Ireland \\ ${ }^{3}$ Marine Scotland Science, Marine Laboratory, Scotland, UK \\ ${ }^{4}$ Centre for Environment, Fisheries and Aquaculture Science, Lowestoft Suffolk United Kingdom \\ ${ }^{5}$ Instituto Español de Oceanografía (IEO), Santander, Spain. \\ ${ }^{6}$ University of Salford, School of Science, England, UK \\ ${ }^{7}$ European Commission, Joint Research Centre (JRC), Ispra, Italy \\ *Correspondence: nrodriguez@azti.es
}

\begin{abstract}
Genetics analyses can reveal mismatches between biological and management units and thus prevent derived ineffective management actions that could lead to serious consequences for fisheries management. Additionally, genetics could reveal other relevant but hidden information such as species misidentification or hybridization. Here, we have assessed the power of genetics to better understand the population connectivity of white angelfish (Lophius piscatorius) and its interaction with its sister species, the black anglerfish (L. budegassa). Our analyses, based on thousands of genome-wide single nucleotide polymorphisms, show three thus far unknown findings that are crucial for white anglerfish management. We found i) that white anglerfish is composed by a single panmictic population throughout the Northeast Atlantic, challenging the three-stock based management, ii) that a fraction of specimens classified as white anglerfish using morphological characteristics are genetically identified as black anglerfish (L. budegassa) and iii) that the two Lophius species naturally hybridize leading to a population of hybrids of up to $20 \%$ in certain areas. Our results set the basics for a genetics-informed white anglerfish assessment framework that accounts for stock connectivity, revises and establishes new diagnostic characters for Lophius species identification and evaluates the effect of hybrids in the current and future assessments of the white anglerfish.
\end{abstract}

Key-words: Lophius piscatorius, Lophius budegassa, genetic connectivity, hybridization, misidentification, SNPs, stock delimitation 


\section{Introduction}

Sustainable exploitation of fisheries resources relies of effective fisheries management actions, which in turn rely on accurate fisheries assessment, that is, the process of synthetizing information on life history, fishery monitoring, and resource surveys for estimating stock size and harvest rate relative to sustainable reference points (Methot and Wetzel, 2013). The process of fisheries assessment is usually applied independently to pre-established management units (so-called stocks), of which parameters such as growth, recruitment, and natural and fishing mortality are assumed to be intrinsic and not dependent on emigration or immigration rates (Cadrin, 2020). Genetic data has demonstrated ability to delineate populations within a species, that is, to identify groups of sexually interbreeding individuals which possess a common gene pool, but has also revealed hidden phenomena such as species misidentification (Garcia-Vazquez et al., 2012) or hybridization (Pampoulie et al., 2020).

Fisheries stocks are often defined upon political and administrative considerations (Stephenson, 2002); yet, failure to align stocks with natural populations results in unfeasibility to establish an accurate relationship between productivity and harvest rates and can result in local reduction of populations and, in extreme cases, to local population collapse (Bonfil, 2005). Mislabeling can be a common phenomenon when morphologically similar species are caught simultaneously, and results in misled exploitation rate estimations when those are based on reported catches (Marko et al., 2004). Hybridization, the successful reproduction between different species (Arnold, 1997; Stronen and Paquet, 2013), has been reported in teleost fishes (Yaakub et al., 2006; Schwenke, 2013), but incidence and associated consequences in commercial fisheries has been scarcely explored (Epifanio and Nielsen, 2000); yet, hybridization could play a key role in diversity loss and even parental species extinction, which has important consequences for management and conservation (Allendorf et al., 2001). An example of species whose management could largely benefit from genetic-derived information is the white anglerfish (Lophius piscatorius, Linnaeus, 1758), a bottom-living fish that moved from being a bycatch species in the last century (Hislop et al., 2001) to become one of the most valuable demersal species in southern and western Europe (ICES, 2010).

Within the Northeast Atlantic, the white anglerfish is managed as three stocks: the Northern Shelf stock (Skagerrak, Kattegat, North Sea, West of Scotland and Rockall), the Northern stock (Celtic Seas and Northern Bay of Biscay) and the Southern Stock (Atlantic and Iberian waters) (ICES, 2019a; ICES, 2019b); yet, the few studies assessing the population structure, based on otolith shape analysis (Cañás et al., 2012), tagging surveys (Laurenson et al., 2005; Landa et al., 2008) and molecular markers, including allozymes (Crozier, 1987), mitochondrial DNA (Charrier et al., 2006) and microsatellites 
(Blanco et al., 2008), did not find differences between stocks. However, this needs to be confirmed with the analysis of a large number of genomic markers, which has been effective in resolving the population structure of marine fish when other markers failed (Rodríguez-Ezpeleta et al., 2016; Leone et al., 2019; Rodríguez-Ezpeleta et al., 2019). The white anglerfish coexists with its sympatric sister species, the black bellied anglerfish (Lophius budegassa), which has a more southern distribution (Relini, 1999; Ungaro et al., 2002). The outer morphology of both species is similar which is why they are often confused, although the color of the epithelium that covers the abdominal cavity, called peritoneum (white in L. piscatorius and black in L. budegassa) is considered a unequivocal diagnostic character for individuals larger than $15 \mathrm{~cm}$ (Caruso, 1986). Yet, genetic analyses based on polymerase chain reaction amplification of restriction fragment length polymorphisms (PCR-RFLP) used for species identification have revealed mislabeling among the two species (Armani et al., 2012).

There is thus a need for resolving the population structure of white anglerfish within the Northeast Atlantic and for understanding its interaction with its sister species, the black anglerfish. For that aim, we have used thousands of genome-wide distributed SNP markers discovered and genotyped through restriction site associated DNA sequencing (RAD-seq) and found i) that white anglerfish from the three stocks within the northeast Atlantic are genetically connected, ii) first evidence of hybridization between white and black anglerfish and iii) records of black anglerfish misidentified as white anglerfish due to a lack of black peritoneum. These findings have important implications for white anglerfish management and conservation, while revealing the enormous advantage of including genomics in fisheries assessment in general.

\section{Material and methods}

\section{Tissue sampling, DNA extraction, and species identification}

Lophius piscatorius $(n=693)$ and Lophius budegassa $(n=31)$ samples were collected from Northeast Atlantic Ocean and Mediterranean Sea locations using scientific surveys and commercial fisheries (Table S1; Figure 1). Sampling of L. piscatorius was carried out so as to cover a large part of the geographic range of this species within the Atlantic, whereas samples of L. budegassa were collected opportunistically as they were only used for comparison purposes. Each individual was assigned to either species by the color of the peritoneum, white for L. piscatorius and black for L. budegassa (Caruso, 1986). Maturity was assigned following the 5 stages key (ICES, 2007). From each individual, a $\sim 1 \mathrm{~cm}^{3}$ muscle tissue sample was excised and immediately stored in $96 \%$ molecular grade ethanol at $-20{ }^{\circ} \mathrm{C}$ until DNA extraction. Genomic DNA was extracted from about $20 \mathrm{mg}$ of muscle tissue using the Wizard ${ }^{\circledR}$ Genomic DNA Purification kit (Promega, WI, USA) following the manufacturer's instructions. Extracted DNA was suspended in Milli-Q water and concentration was determined with the Quant-iT dsDNA 
HS assay kit using a Qubit ${ }^{\circledR}$ 2.0 Fluorometer (Life Technologies). DNA integrity was assessed by electrophoresis, migrating about $100 \mathrm{ng}$ of Sybr ${ }^{\mathrm{TM}}$ Safe-stained DNA on an agarose $1.0 \%$ gel. A polymerase chain reaction restriction fragment length polymorphism (PCR-RFLP) method (Armani et al., 2012) was used for authentication of all specimens collected. In order to further validate the PCR-RFLP results, for 122 of the samples, a fragment of the cytochrome $b$ (cytb) gene was amplified with the primers GluFish-F and THR-Fish-R (Sevilla et al., 2007) using the following amplification conditions: denaturation at $95^{\circ} \mathrm{C}$ for $3 \mathrm{~min} ; 35$ cycles at $95^{\circ} \mathrm{C}$ for $30 \mathrm{~s}, 57^{\circ} \mathrm{C}$ for $30 \mathrm{~s}, 72$ ${ }^{\circ} \mathrm{C}$ for $60 \mathrm{~s}$; and final extension at $72{ }^{\circ} \mathrm{C}$ for $10 \mathrm{~min}$. The PCR products were purified and sequenced using Sanger.

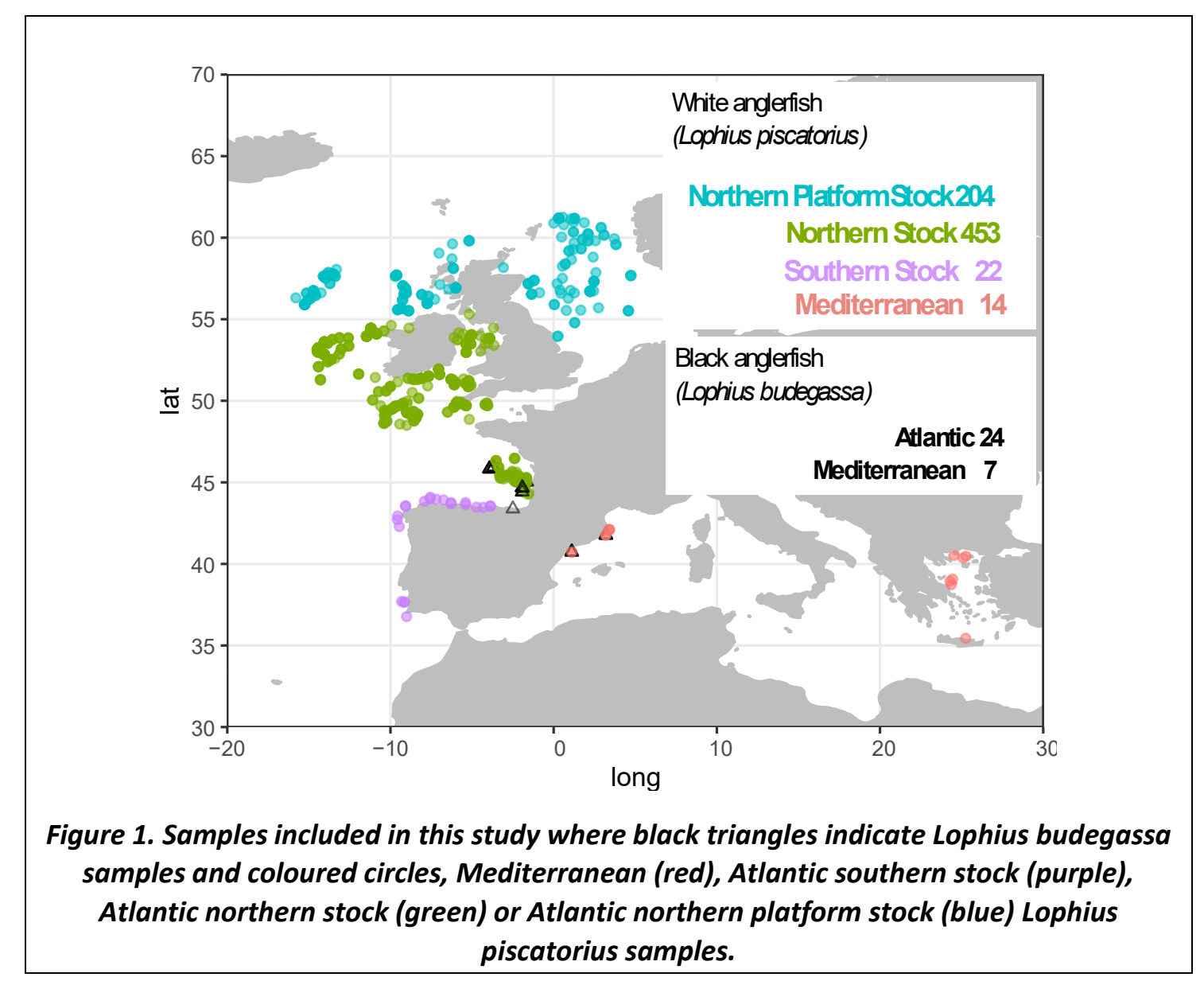

\section{RAD-seq library preparation and sequencing}

Restriction-site-associated DNA libraries were prepared for $306 \mathrm{~L}$. piscatorius and $27 \mathrm{~L}$. budegassa individuals (Table S1) following the methods of Etter et al. (2012). 5 individuals were run by duplicate starting from the tissue sample to check for replicability. Between 300 and $600 \mathrm{ng}$ of starting DNA (depending on integrity) was digested with the $S b f I$ restriction enzyme and ligated to modified Illumina P1 adapters containing $5 \mathrm{bp}$ sample-specific barcodes. Pools of 32 individuals were sheared using the Covaris $^{\circledR}$ M220 Focused-ultrasonicator ${ }^{\mathrm{TM}}$ Instrument (Life Technologies) and size 
selected to 300-500 bp with magnetic beads. Following the Illumina P2 adaptor ligation, each library was amplified using 12 PCR cycles and batches of three pools were pairedend sequenced (100 bp) on an Illumina HiSeq4000.

\section{SNP genotype table generation}

Generated RAD-tags were analyzed using Stacks version 2.4 (Catchen et al., 2013). Quality filtering and demultiplexing were performed using the Stacks module process_radtags removing reads with ambiguous bases and with an average quality score lower than 20 in at least one stretch of 15 nucleotides and using a maximum of 1 mismatch when rescuing single-end barcodes. Only reads whose forward and reverse pair passed quality filtering were kept and the module clone filter was applied to remove PCR duplicates. De novo and reference-based assemblies were performed for consistency. For the de novo assembly, the module ustacks was used to assemble filtered reads into putative orthologous loci per individual, with a minimum coverage depth required to create a stack (parameter $-\mathrm{m}$ ) of 3 , and a maximum nucleotide mismatches allowed between stacks (parameter -M) of 4. RAD-loci were then assembled using the module cstacks with a maximum of 6 allowed mismatches between sample loci when generating the catalogue (parameter $-n$ ). Matches to the catalogue for each sample were searched using sstacks and transposed using tsv2bam. For the reference mapped assembly, the filtered reads were mapped against the available draft white anglerfish genome (Dubin et al., 2019) using the BWA-MEM algorithm (Li, 2013), and the resulting SAM files converted to BAM format, sorted and indexed using SAMTOOLS (Li et al., 2009). Mapped reads were filtered to include only primary alignments and correctly mate mapped reads. The following steps were applied to both the de novo and reference mapped catalogs including only samples with a minimum of 30,000 RAD-loci. Paired-end reads were assembled into contigs and SNPs derived were identified and genotyped using the module gstacks. For each subset of individuals to be analyzed (Table S2), the module populations was used to select the tags present in RAD-loci found in at least $90 \%$ of the individuals, and PLINK version 1.07 (Purcell et al., 2007) was used to select samples with a minimum of 0.85 genotyping rate, and SNPs with a minimum of 0.95 genotyping rate and a minimum allele frequency (MAF) bigger than 0.05. Tags on which the selected SNPs were located were mapped against the complete mitochondrial genome of Lophius piscatorius (NC_036988.1) with the BWA-MEM algorithm (Li, 2013) to exclude the possibility that the final genotype dataset contained mitochondrial SNPs.

\section{Genetic diversity, population structure and hybridization analyses}

The following analyses were performed using only the first SNP per tag. Expected (He) and observed $(\mathrm{Ho})$ heterozygosity and average pairwise $\mathrm{F}_{S T}$ values were computed with PLINK (Purcell, 2009) and GENEPOP (Rousset, 2014) respectively. Principal component analysis (PCA) was performed without any a priori assignment of individuals to populations using the package adegenet (Jombart and Ahmed, 2011) in R version 3.5.0 
(Team, 2018). The genetic ancestry of each individual was estimated using the modelbased clustering method implemented in ADMIXTURE (Alexander et al., 2015) assuming from 2 to 5 ancestral populations $(K)$ and setting 1000 bootstrap runs. The value of $K$ with lowest associated error value was identified using the ADMIXTURE's crossvalidation procedure assuming from 1 to 5 ancestral populations. Using NewHybrids (Anderson and Thompson, 2002), posterior probabilities of each individual's membership as a pure parent, first (F1) or second (F2) generation hybrids or backcrosses were calculated applying default parameters to the 200 SNPs with less than $1 \%$ of missing data that presented the highest Fst between genetically assigned L. piscatorious and L. budegassa samples.

\section{Abundance distribution maps}

White and black anglerfish catch data from trawl surveys targeting anglerfish (BITS, NSIBTS, SWC-IBTS, EVHOE, SP-NORTH, SP-ARSA, ROCKALL, PT-IBTS, IE-IGFS, NIGFS, DWS, SCOROC, SCOWCGFS, IE-IAMS, FR-CGFS) conducted between 1995 and 2019 was retrieved from the ICES Database of Trawl Surveys using the icesDatras $R$ library (https://github.com/ices-tools-prod/icesDatras). Using information for each haul (latitude, longitude, haul duration and catch weight per species), data was aggregated by five consecutive years and ICES statistical rectangles and converted to $\mathrm{g} / \mathrm{min}$ per species. For those hauls with catch data as number of individuals instead of weight, weight was estimated using weight-length relationships. For each five-year period and rectangle, $\mathrm{g} / \mathrm{min}$ per species was plotted in a gradient from white (minimum abundance) to red (maximum abundance) using grey to represent areas where sampling was performed but no catch was reported.

\section{Results}

\section{Genetically distinct groups that are not related to sampling location}

The genotype table including individuals from both species resulted in 323 and 327 individuals (of which 27 were L. budegassa) and 16712 or 23126 SNPs after filtering when using a de novo or reference mapped assembly respectively (Table S2). Replicates resulted in $0.9947 \%$ identical genotypes. The PCA and ADMIXTURE analyses based on these datasets grouped most samples in three clearly distinguishable groups and results were virtually identical among the de novo and reference assembly datasets (Figure 2; Figure S1). In the PCA (Figure 2A), all samples except five of them that could not be clearly assigned to any of the three groups, are disposed along the first principal component (accounting for $80.82 \%$ of the total variancumeroe): the first group includes L. piscatorius individuals from all locations, the second group includes $L$. piscatorius individuals from all locations except the Southern Stock, and the third group includes $L$. piscatorius individuals from all locations except the Northern Shelf Stock and $L$. budegassa individuals. These groups are coherent with the different types of genetic 
admixture patterns observed, which supports two ancestral populations (Figure 2B; Figure S2): samples classified in Group 1 and Group 3 in the PCA are not admixed and belong to different ancestral populations and samples classified in Group 2 in the PCA are admixed with equal contribution from both ancestral populations. Samples located between Groups 1 and 2 and between Groups 2 and 3 show consistent patterns in admixture analyses with about $75 \%$ or $25 \%$ of contribution from Groups 1 and 3, respectively.

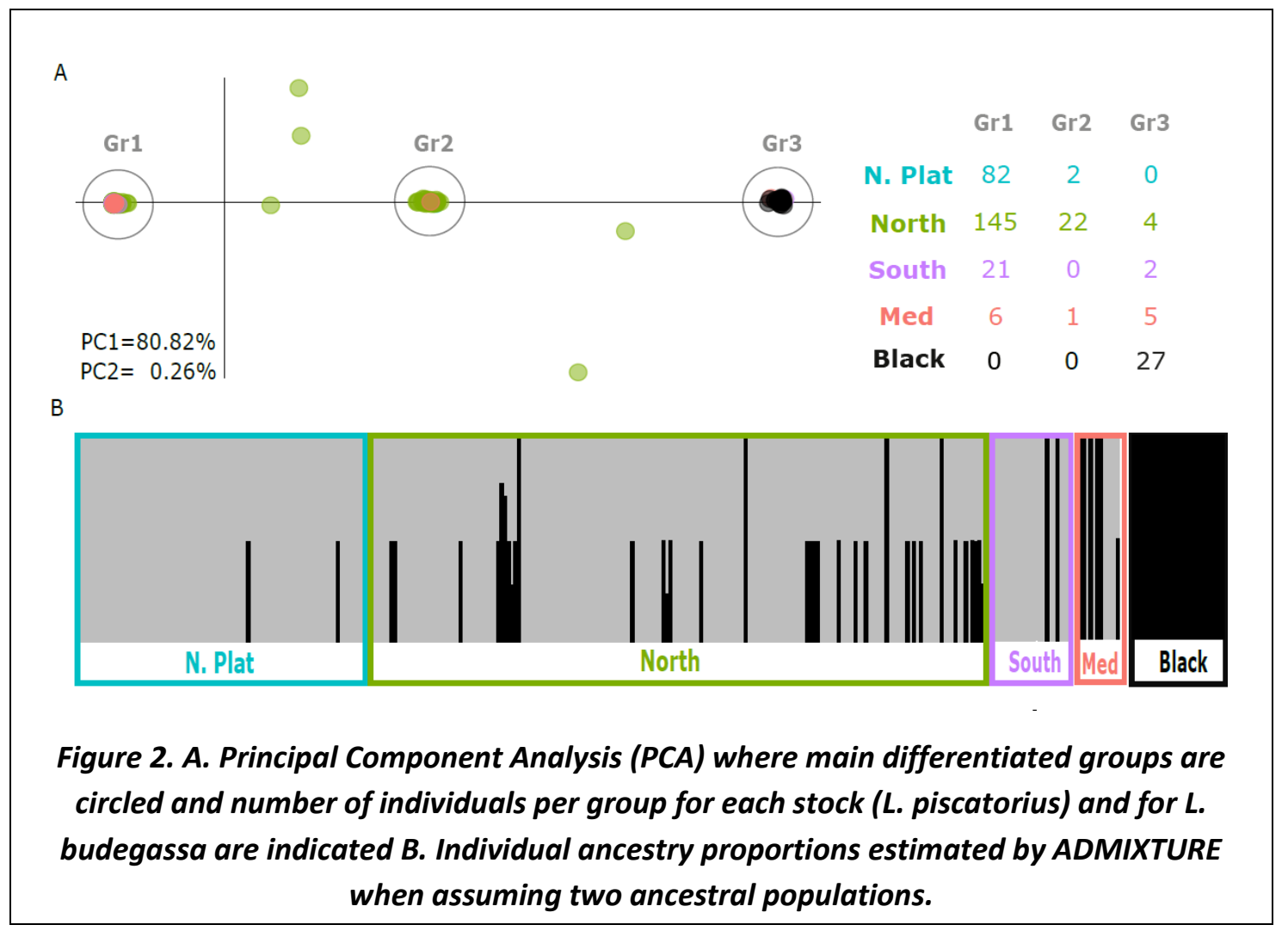

\section{Misidentification and hybridization}

Together, these results indicate that some of the samples that were morphologically identified as L. piscatorius (Group 3) are actually L. budegassa, which is confirmed by mitochondrial DNA analyses that identify all samples in Group 1 as L. piscatorius and all samples in Group 3 as L. budegassa. Samples in Group 2 and between this group and the other two have a significantly higher observed average heterozygosity (0.77) than Groups 1 and Groups 3 (0.05 and 0.03, respectively), which could indicate that these individuals are hybrids. This was confirmed by NewHybrids, which assigned all individuals in Group 2 as new generation hybrids between the two species (F1), and the five remaining individuals as backcrosses between $\mathrm{F} 1$ hybrids and white or black anglerfish. Mitochondrial DNA from all hybrids except for $3 \mathrm{~F} 1$ was of L. budegassa. Overall, we found about 4 and $10 \%$ misidentified and hybrid individuals, respectively. However, 
these were not distributed homogeneously across the study area (Figure 3). Misidentified individuals were more present in the most southern region of the Southern stock (Portuguese coast) and Mediterranean Sea, with $1 / 3$ of the individuals identified as $L$. piscatorius being L. budegassa, less frequent in the Northern stock (2\%), and absent in Northern Shelf stock. Hybrid individuals were absent in the Southern stock and North Sea (belonging to the Northern Shelf stock) and were most frequent in the northern Bay of Biscay and Celtic seas (13\%).

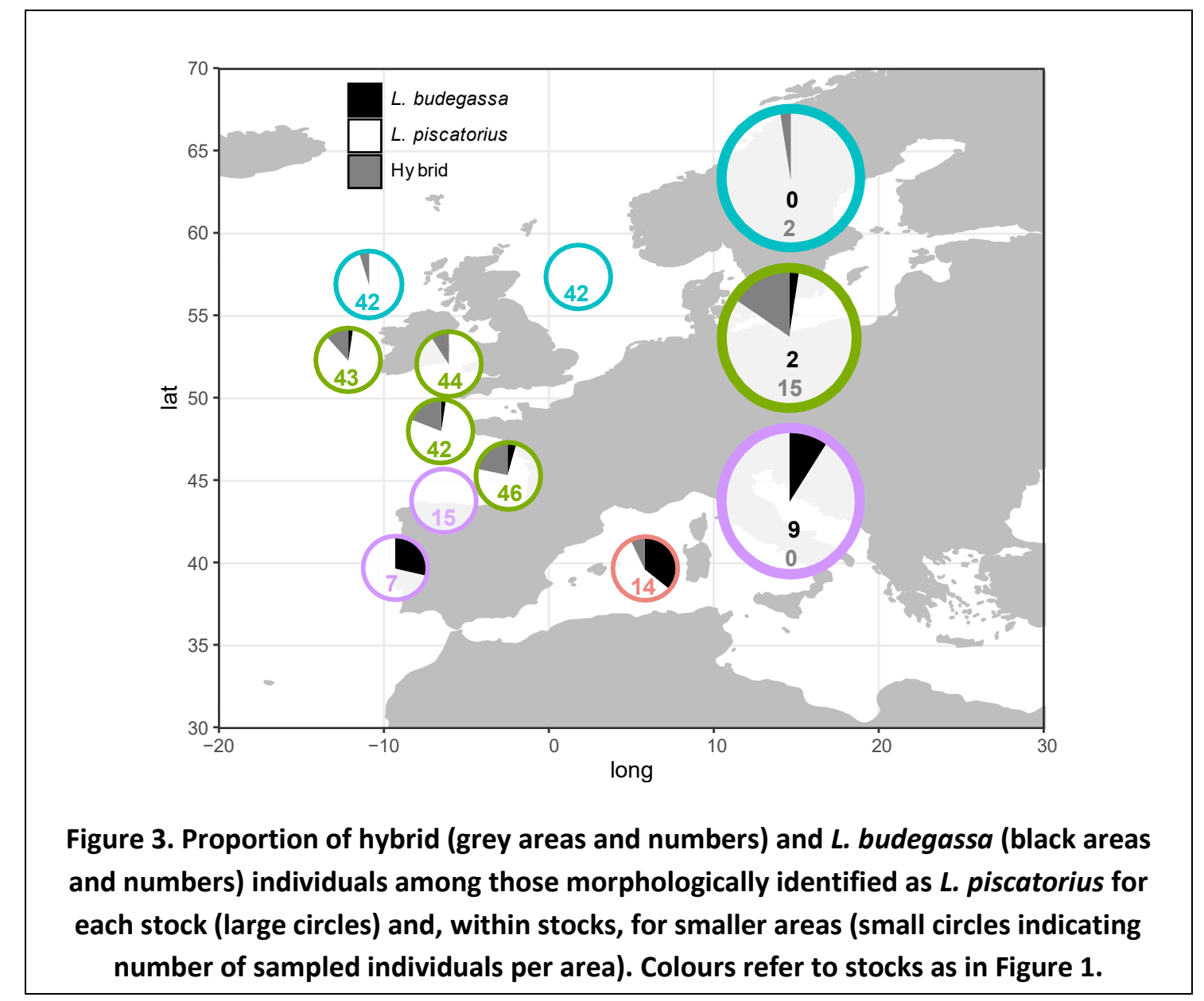

\section{Connectivity of white anglerfish within the Atlantic}

The genotype table including only those individuals genetically identified as L. piscatorius include 238 or 232 individuals and 6233 or 6246 SNPs when including or not Mediterranean samples, respectively. PCA and ADMIXTURE analyses based on those datasets (Figure 4) reveal strong differentiation between Mediterranean and Atlantic samples $\left(F_{S T}=0.057\right)$ and no genetic differentiation within the Atlantic $\left(F_{S T}=0\right)$. 
A
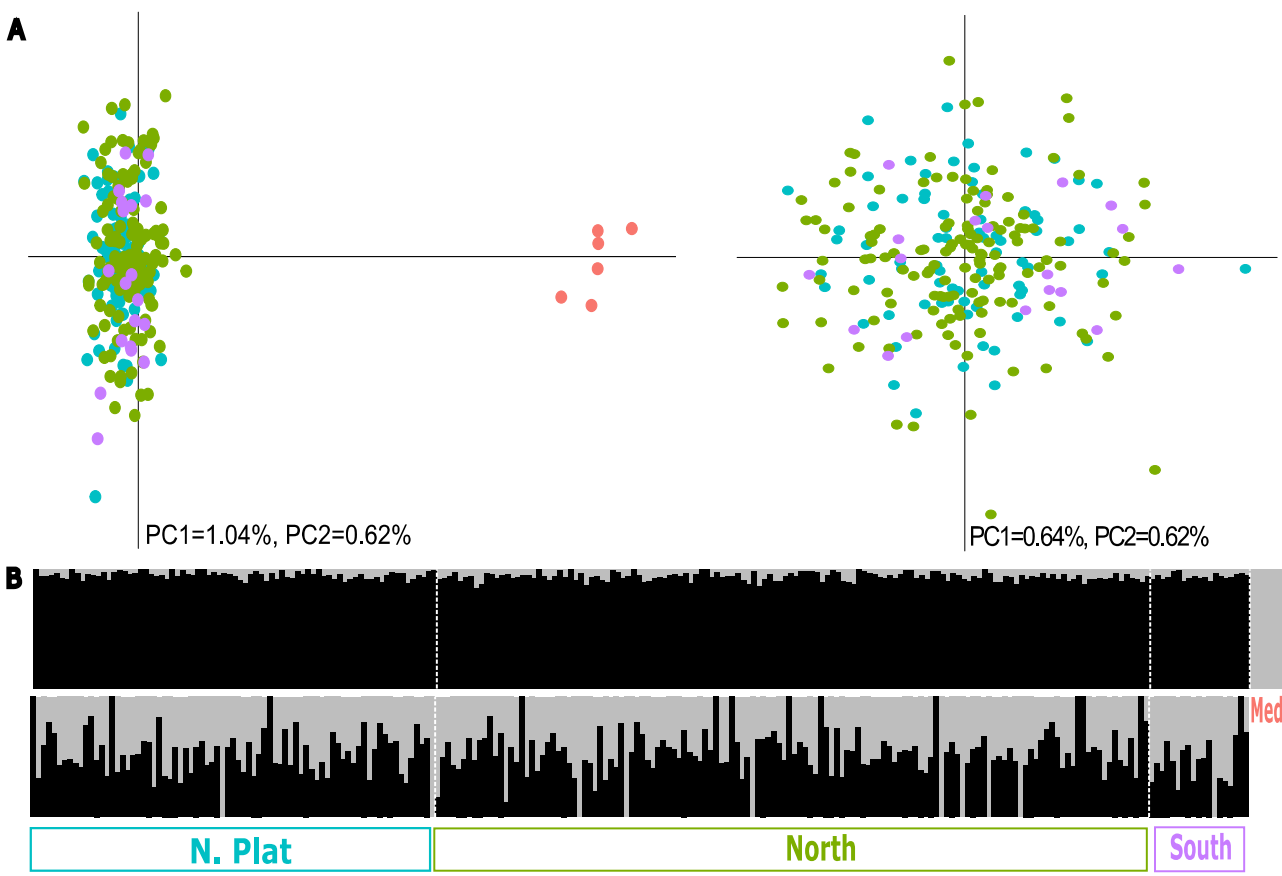

Figure 4. A. Principal Component Analysis (PCA) of samples genetically identified as white anglerfish when including (left) or not (right) Mediterranean samples. B. Individual ancestry proportions of samples genetically identified as white anglerfish estimated by ADMIXTURE when assuming two ancestral populations including (above) or not (below)

Mediterranean samples.

\section{Discussion}

\section{What's in a white anglerfish sample?}

We found that several of the samples provided as white anglerfish (Lophius piscatorius) by expert scientists involved in surveys targeting anglerfish were indeed black anglerfish or hybrids. This implies that the commonly used diagnostic character for species identification, the color of the peritoneum, is not discriminative as all the black anglerfish and hybrid individuals provided as white anglerfish had white peritoneum. Indeed, it has already been suggested that some young individuals cannot be distinguished by the color of the peritoneum (e.g. some that show a white peritoneum with small black dots can be assigned to either black or white anglerfish when using another diagnostic character such as the number of dorsal fins rays (J. Landa and A. Antolínez, unpublished data). Here, we found misidentified individuals that are large (up to $75 \mathrm{~cm}$ ) (Figure 5), suggesting that the reason for misidentification is not related to the size of the specimens. In light of these findings, alternative characteristics for species identification are needed (e.g. dorsal and anal fin ray counts or length of the cephalic dorsal fin spines (Caruso, 1986)), so that misidentification does not affect data 
collection. Additionally, a way of identifying hybrids would be needed. Notably, in our dataset, the hybrid size distributions was significantly smaller than that of the $L$. piscatorius individuals ( $p<0.05$ in the Mann-Whitney test), although the small sample size of hybrids and confounding factors (e.g. different proportion of hybrids in the different stocks, age classes) prevent drawing conclusions from this fact at this stage.

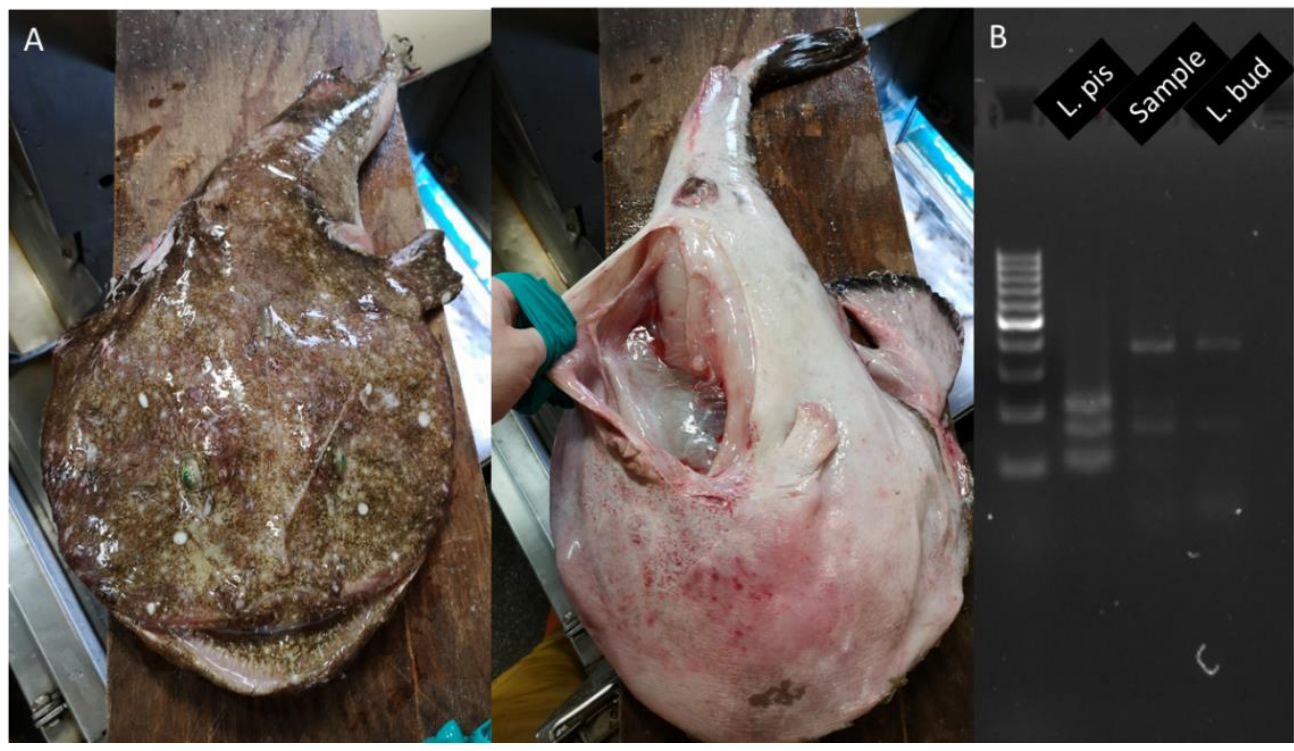

Figure 5. A. Specimen of anglerfish captured in the northern coast of Scotland $165 \mathrm{~cm}$ and $4.4 \mathrm{~kg}$ ) with white peritoneum, emerald green eyes, and stippled skin, genetically identified as black anglerfish. B. Agarose gel electrophoresis of the resulting PCR-RFLP band for white (L. pis) and black anglerfish (L. bud) showing that this specimen (Sample) is genetically identified as black anglerfish.

\section{Causes and consequences the interspecific hybridization}

We provide, to the best of our knowledge, the first evidence of natural hybridization between Lophius piscatorius and L. budegassa, a phenomenon that can occur between closely related species sharing morphological, ecological and reproductive compatibilities (Montanari et al., 2014). Lophius spp. hybrids were predominant in Northern Bay of Biscay and Celtic seas, were both species' distribution range overlap and have been historically abundant (Figure 6). There is also overlap in both species' bathymetric distribution (20-1000m and 100-500m depth respectively for white and black anglerfish)(Caruso, 1986; Azevedo, 1995; Quincoces et al., 1998; García-Rodríguez et al., 2005), and in spawning periods, both spawning in winter and spring (Quincoces, 2002.; Ofstad et al., 2013). This overlap in space, depth and time could have even been increased by recent changes of geographical and bathymetric distributions of both species, potentially as consequence of climate change (Maltby et al., 2020). According to mitochondrial DNA, which is maternally inherited in most animals (Moritz et al., 
1987), we found that most hybrids (27 out of 30 ) resulted from a black anglerfish mother and a white anglerfish father. We found a few backcrosses (hybrids crossed with parental species) and no crosses involving two hybrids. This could be due the presence of a stable hybrid zone with hybrids being less able to produce offspring (Hayden et al., 2010; Mirimin et al., 2014) or to recent changes that have induced hybridization between both species so newly that they did not have time to produce a hybrid-derived population. The presence of a stable hybrid zone between black and white anglerfish does not forcedly imply changes in the evolution of the parental species but could imply management uncertainties. However, if hybridization is recent, we cannot discard a process of evolutionary novelty (Budd and Pandolfi, 2010), through parental species acquiring new functions (Anderson et al., 2009) and even producing new species (Verheyen et al., 2003), or of biodiversity loss, through extinction of parental species (Seehausen, 2006). Thus, monitoring the hybrid zone and adjacent areas is crucial to understand the role of hybridization in management and conservation of white and black anglerfish.
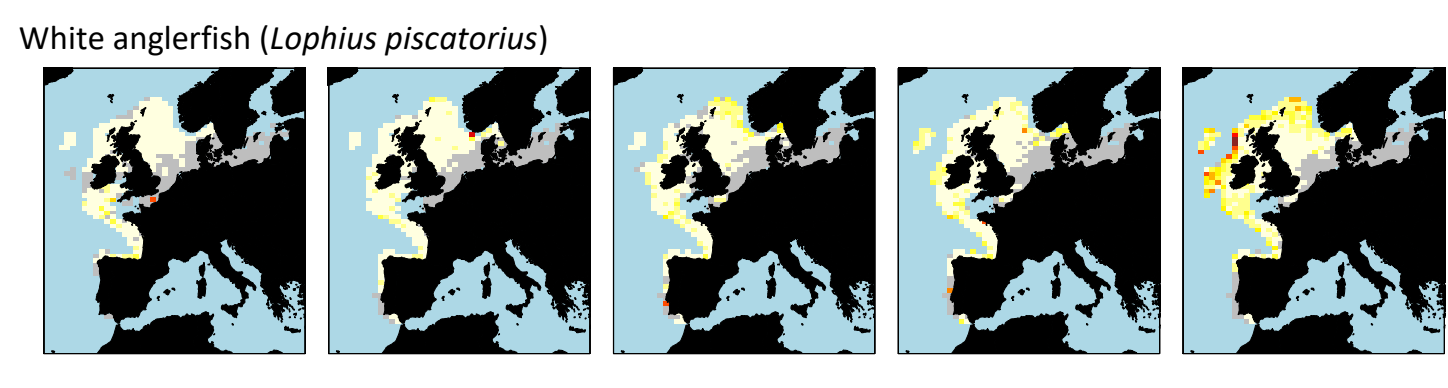

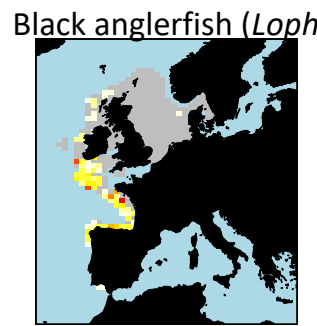

1995-1999

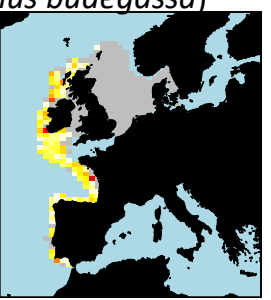

$2000-2004$

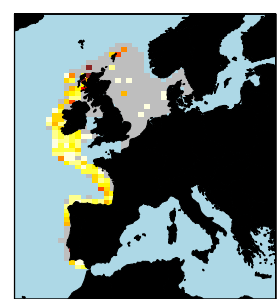

2005-2009

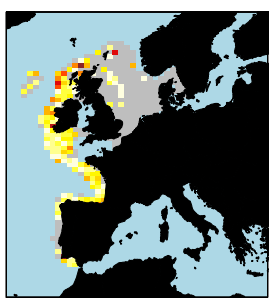

2010-2014

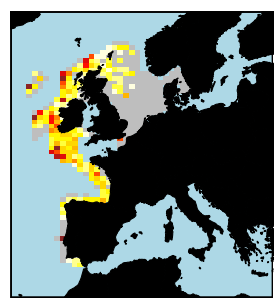

2015-2019

Figure 6. Maps showing catch per trawl time (g/min) for white (top) and black (bottom) anglerfish grouped in five-year periods from 1995 to 2019. Colours range from white to dark red representing overall lowest to highest $\mathrm{g} / \mathrm{min}$ per species (maximum values are 2053 and 335 for white and black anglerfish, respectively). Grey represents areas where sampling was conducted but no specimens were captured.

\section{Management implications of stock connectivity, hybridization and misidentification}

Our results suggest that the white anglerfish within the Northeast Atlantic Ocean constitutes a genetically homogeneous population, which confirms previous findings based on genetic and non-genetic data (Crozier, 1987; Laurenson et al., 2005; Charrier 
et al., 2006; Blanco et al., 2008; Landa et al., 2008; Cañás et al., 2012) and point towards the necessity to harmonize current stock definitions. Morphometric characteristics such as length of maturity (Duarte et al., 2001) or weight-length relationships (Landa and Antolínez, 2018) differ between stocks. These differences are potentially due to sampling biases, differences in scales and/or measurement methods or interannual differences among studies, as well as the possible influence of different fishing pressure or environmental conditions between areas. However, they could also be due to the inclusion of different proportions of misidentified and hybrid individuals in each stock. Although in the Northern and Southern stocks the assessment is done separately for white and black anglerfish, they are combined for management, being Total Allowable Catches (TAC) for Lophius spp. In the Northern Shelf stock, the two species are assessed and managed as one assuming that black anglerfish in this area are rare. However, the obvious increase of black anglerfish in this stock (Figure 6) has created concern and suggestions to separate species have been made (ICES, 2018). The deliberate (in the North Shelf stock) or non-deliberate (in the Northern and Southern stocks) inclusion of an unknown (and perhaps variable) proportion of black anglerfish in the white anglerfish assessment will likely lead to some bias. Therefore, some corrections could be applied to the total catches and the length composition data. However, the proportions of black anglerfish included in these assessments seem relatively small $(<10 \%)$ and would likely not have a major impact on the assessments. The implications of including hybrids in the stock assessment are more difficult to anticipate as biological characteristics of hybrids are unknown. The main concern is that inclusion of hybrids would lead to erroneous inferences of reproductive potential because this feature is inferred from the biomass of mature fish and the reproductive output of anglerfish hybrids is unknown. If, as in many other species (Mallet, 2007), they have no or neglectable offspring, they should not be included in the spawning biomass as otherwise they could lead to an overestimation of productivity, even to a level below of required to support a sustainable fishery (Morgan et al., 2012). On the other hand, if, as the presence of backcrossed individuals suggest, they are reproductively viable, further studies are required to assess hybrid fitness compared to pure individuals.

Despite supporting stock merging, the analyses presented here suggest a series of concerns that should be considered for white anglerfish management and which affect differently each of the stocks. The southernmost locations of the Southern Stock and the Mediterranean Sea are more affected by misidentification, the northernmost locations of the Northern stock are more affected by hybridization, and the North Shelf stock does not seem to be affected by any of them. The over and under representation of misidentified individuals (black anglerfish with white peritoneum) in the south and north respectively could be simply explained by differences in black anglerfish abundance. However, both species are moving northwards, and so the proportion of misidentified individuals could increase in northern areas as black anglerfish becomes more abundant. This northward movement of both species could also contribute to 
enlarge the hybrid zone towards northern areas. If the proportion of hybridization and mislabeling varies significantly over time, then this will have implications for the robustness of the assessment for these stocks. Thus, genetic studies monitoring white and black anglerfish populations across the Northeast Atlantic and Mediterranean Sea through time are needed.

\section{Outlook}

Our study shows that genetic analyses can be used to confirm or reject existing hypothesis about, for example, stock connectivity but, most importantly, that they can reveal hidden phenomena that were not foreseen, such as the thus far unknown hybridization between white and black anglerfish. Yet, despite the power of genetics to provide fisheries assessment relevant information, there are still barriers for the uptake of genetic data by fisheries management, which can be due to a variety of factors (Ovenden Jennifer et al., 2013; Bernatchez et al., 2017), such as lack of clear communication of genetic concepts by geneticists to end-users and reluctance to change or adapt established assessment and management procedures. Being the white anglerfish a high valuable species (around $30 \mathrm{~K}$ tons with a corresponding value of around 142 million euro; data extracted from https://stecf.jrc.ec.europa.eu/dd/fdi) with a well stablished data collection, assessment and management frameworks, we anticipate that these results will set the basics for an imminent genetics informed fisheries management for this species, without which the foundations of fisheries science, whereby maximum sustainable yield can only be reached by efficient management of distinct populations, is threatened.

\section{Acknowledgements}

We would like to thank Arkaitz Pedrajas and Arnaitz Mugerza (AZTI), Liz Clarke, Jim Drewery and Ruadhan Gillespie-Mules (MSS, Scotland), Eoghan Kelly and David Tully (MI, Ireland), Jose Carlos Fernández Franco, Ángela Cortina Burgueño and Oscar Fernández Acevedo (OPPF-4, Spain), the fisheries surveys team (CEFAS), Izaskun Preciado and Susana Ruiz (IEO), Corina Chaves (IPMA, Portugal), Anabel Colmenero (ICM-CSIC, Spain), Chrysoula Gubili (FRI, Greece) and Nota Peristeraki (HCRM, Greece) for sampling and Elisabete Bilbao for laboratory work. This work has been funded by the Joint Research Centre (European Commission), through the project GECKA (Contract JRC/IPR/2017/D.2/0016/NC), the Department of Environment, Planning, Agriculture and Fisheries (Basque Government), through the project GENGES and a predoctoral grant to Imanol Aguirre-Sarabia, and by the Department of Education (Basque Government), through a predoctoral grant to Iker Pereda.

\section{References}

Alexander, D. H., Shringarpure, S. S., Novembre, J., and Lange, K. 2015. Admixture 1.3 software manual. Los Angeles: UCLA Human Genetics Software Distribution. 
Allendorf, F., Leary, R. F., Spruell, P., and Wenburg, J. 2001. The problems with hybrids: setting conservation guidelines. Trends in Ecology and Evolution, 16: 613-622.

Anderson, E., and Thompson, E. 2002. A model-based method for identifying species hybrids using multilocus genetic data. Genetics, 160: 1217-1229.

Anderson, T. M., Candille, S. I., Musiani, M., Greco, C., Stahler, D. R., Smith, D. W., Padhukasahasram, B., et al. 2009. Molecular and evolutionary history of melanism in North American gray wolves. Science, 323: 1339-1343.

Armani, A., Castigliego, L., Tinacci, L., Gandini, G., Gianfaldoni, D., and Guidi, A. 2012. A rapid PCR-RFLP method for the identification of Lophius species. European Food Research and Technology, 235: 253-263.

Arnold, M. L. 1997. Natural hybridization and evolution, Oxford University Press on Demand.

Azevedo, M. 1995. A statistical analysis of black monkfish catch rates in ICES Division IXa. Fisheries Research, 24: 281-289.

Bernatchez, L., Wellenreuther, M., Araneda, C., Ashton, D. T., Barth, J. M. I., Beacham, T. D., Maes, G. E., et al. 2017. Harnessing the Power of Genomics to Secure the Future of Seafood. Trends in Ecology \& Evolution, 32: 665-680.

Blanco, G., Borrell, Y., Cagigas, M., Vázquez, E., and Prado, J. S. 2008. Microsatellites-based genetic analysis of the Lophiidae fish in Europe. Marine and Freshwater Research, 59: 865-875.

Bonfil, R. 2005. Management Techniques for Elasmobranch Fisheries. In FAO Fisheries Technical Paper 474, pp. 6-14. Ed. by R. B. John Musick. FAO.

Budd, A. F., and Pandolfi, J. M. 2010. Evolutionary novelty is concentrated the edge of coral species distributions. Science, 328: 1558-1561.

Cadrin, S. X. 2020. Defining spatial structure for fishery stock assessment. Fisheries Research, 221: 105397.

Cañás, L., Stransky, C., Schlickeisen, J., Sampedro, M. P., and Fariña, A. C. 2012. Use of the otolith shape analysis in stock identification of anglerfish (Lophius piscatorius) in the Northeast Atlantic. ICES Journal of Marine Science, 69: 250-256.

Caruso, J. 1986. Lophiidae. Fishes of the North-eastern Atlantic and the Mediterranean, 3: 13621363.

Catchen, J., Hohenlohe, P. A., Bassham, S., Amores, A., and Cresko, W. A. 2013. Stacks: an analysis tool set for population genomics. Molecular Ecology, 22: 3124-3140.

Crozier, W. 1987. Biochemical genetic variation and population structure in angler-fish Lophius piscatorius L. from the Irish Sea and west of Scotland. Journal of Experimental Marine Biology and Ecology, 106: 125-136.

Charrier, G., Chenel, T., Durand, J. D., Girard, M., Quiniou, L., and Laroche, J. 2006. Discrepancies in phylogeographical patterns of two European anglerfishes (Lophius budegassa and Lophius piscatorius). Molecular Phylogenetics and Evolution, 38: 742-754.

Duarte, R., Azevedo, M., Landa, J., and Pereda, P. 2001. Reproduction of anglerfish (Lophius budegassa Spinola and Lophius piscatorius Linnaeus) from the Atlantic Iberian coast. Fisheries Research, 51: 349-361.

Dubin, A., Jørgensen, T. E., Moum, T., Johansen, S. D., and Jakt, L. M. 2019. Complete loss of the MHC II pathway in an anglerfish, Lophius piscatorius. Biology Letters, 15: 20190594.

Epifanio, J., and Nielsen, J. 2000. The Role of Hybridization in the Distribution, Conservation and Management of Aquatic Species. Reviews in Fish Biology and Fisheries, 10: 245-251. 
Etter, P. D., Bassham, S., Hohenlohe, P. A., Johnson, E. A., and Cresko, W. A. 2012. SNP discovery and genotyping for evolutionary genetics using RAD sequencing. In Molecular methods for evolutionary genetics, pp. 157-178. Springer.

García-Rodríguez, M., Pereda, P., Landa, J., and Esteban, A. 2005. On the biology and growth of the anglerfish Lophius budegassa Spinola, 1807 in the Spanish Mediterranean: a preliminary approach. Fisheries Research, 71: 197-208.

Garcia-Vazquez, E., Machado-Schiaffino, G., Campo, D., and Juanes, F. 2012. Species misidentification in mixed hake fisheries may lead to overexploitation and population bottlenecks. Fisheries Research, 114: 52-55.

Hayden, B., Pulcini, D., Kelly-Quinn, M., O'Grady, M., Caffrey, J., McGrath, A., and Mariani, S. 2010. Hybridisation between two cyprinid fishes in a novel habitat: genetics, morphology and life-history traits. BMC Evolutionary Biology, 10: 169.

Hislop, J. R., Gallego, A., Heath, M. R., Kennedy, F. M., Reeves, S. A., and Wright, P. J. 2001. A synthesis of the early life history of the anglerfish, Lophius piscatorius (Linnaeus, 1758) in northern British waters. ICES Journal of Marine Science, 58: 70-86.

ICES. 2007. Report of the Workshop on Sexual Maturity Staging of Hake and Monk (WKMSHM), 21-24 November 2007, Lisbon, Portugal. ICES CM 2007/ACFM:34. 82 pp.

ICES. 2010. Report of the Working Group on the Assessment of Southern Shelf Stocks of Hake, Monk and Megrim (WGHMM), 5 - 11 May 2010, Bilbao, Spain, ICES Document CM 2010/ACOM:11. 599 pp.

ICES. 2018. Report of the Benchmark Workshop on Anglerfish Stocks in the ICES Area (WKANGLER), 12-16 February 2018, Copenhagen, Denmark. ICES CM 2018/ACOM:31. $177 \mathrm{pp}$.

ICES. 2019a. Working Group for the Bay of Biscay and the Iberian waters Ecoregion (WGBIE). ICES Scientific Reports. 1:31. 692 pp. http://doi.org/10.17895/ices.pub.5299.

ICES 2019b. Working Group for the Celtic Seas Ecoregion (WGCSE). ICES Scientific Reports. 1:29. 1078 pp. http://doi.org/10.17895/ices.pub.4982.

Jombart, T., and Ahmed, I. 2011. adegenet 1.3-1: new tools for the analysis of genome-wide SNP data. Bioinformatics, 27: 3070-3071.

Landa, J., and Antolínez, A. 2018. Weight-length relationships, weight conversion factors and somatic indices from two stocks of black anglerfish (Lophius budegassa) and white anglerfish (L. piscatorius) in north-eastern Atlantic waters. Regional Studies in Marine Science, 23: 87-96.

Landa, J., Quincoces, I., Duarte, R., Fariña, A. C., and Dupouy, H. 2008. Movements of black and white anglerfish (Lophius budegassa and L. piscatorius) in the northeast Atlantic. Fisheries Research, 94: 1-12.

Laurenson, C. H., Johnson, A., and Priede, I. G. 2005. Movements and growth of monkfish Lophius piscatorius tagged at the Shetland Islands, northeastern Atlantic. Fisheries Research, 71: 185-195.

Leone, A., Álvarez, P., García, D., Saborido-Rey, F., and Rodriguez-Ezpeleta, N. 2019. Genomewide SNP based population structure in European hake reveals the need for harmonizing biological and management units. ICES Journal of Marine Science.

Li, H. 2013. Aligning sequence reads, clone sequences and assembly contigs with BWA-MEM. arXiv preprint arXiv:1303.3997. 
Li, H., Handsaker, B., Wysoker, A., Fennell, T., Ruan, J., Homer, N., Marth, G., et al. 2009. The sequence alignment/map format and SAMtools. Bioinformatics, 25: 2078-2079.

Maltby, K. M., Rutterford, L. A., Tinker, J., Genner, M. J., and Simpson, S. D. 2020. Projected impacts of warming seas on commercially fished species at a biogeographic boundary of the European continental shelf. Journal of Applied Ecology, n/a.

Mallet, J. 2007. Hybrid speciation. Nature, 446: 279-283.

Marko, P. B., Lee, S. C., Rice, A. M., Gramling, J. M., Fitzhenry, T. M., McAlister, J. S., Harper, G. R., et al. 2004. Fisheries: mislabelling of a depleted reef fish. Nature, 430: 309-310.

Methot, R. D., and Wetzel, C. R. 2013. Stock synthesis: A biological and statistical framework for fish stock assessment and fishery management. Fisheries Research, 142: 86-99.

Mirimin, L., Kerwath, S., Macey, B., Bester-van der Merwe, A., Lamberth, S., Bloomer, P., and Roodt-Wilding, R. 2014. Identification of naturally occurring hybrids between two overexploited sciaenid species along the South African coast. Molecular Phylogenetics and Evolution, 76: 30-33.

Montanari, S. R., Hobbs, J. P. A., Pratchett, M. S., Bay, L. K., and Van Herwerden, L. 2014. Does genetic distance between parental species influence outcomes of hybridization among coral reef butterflyfishes? Molecular Ecology, 23: 2757-2770.

Morgan, J. A. T., Harry, A. V., Welch, D. J., Street, R., White, J., Geraghty, P. T., Macbeth, W. G., et al. 2012. Detection of interspecies hybridisation in Chondrichthyes: hybrids and hybrid offspring between Australian (Carcharhinus tilstoni) and common (C. limbatus) blacktip shark found in an Australian fishery. Conservation Genetics, 13: 455-463.

Moritz, C., Dowling, T., and Brown, W. 1987. Evolution of animal mitochondrial DNA: relevance for population biology and systematics. Annual Review of Ecology and Systematics, 18: 269-292.

Ofstad, L., Angus, C., Pedersen, T., and Steingrund, P. 2013. Age and growth of anglerfish (Lophius piscatorius) in Faroese waters. Fisheries Research, 139: 51-60.

Ovenden Jennifer, R., Berry, O., Welch David, J., Buckworth Rik, C., and Dichmont Catherine, M. 2013. Ocean's eleven: a critical evaluation of the role of population, evolutionary and molecular genetics in the management of wild fisheries. Fish and Fisheries, 16: 125-159.

Pampoulie, C., Gíslason, D., Ólafsdóttir, G., Chosson, V., Halldórsson, S. D., Mariani, S., Elvarsson, B., et al. 2020. Evidence of unidirectional hybridization and second-generation adult hybrid between the two largest animals on Earth, the fin and blue whales. Evolutionary Applications, n/a.

Purcell, S. 2009. PLINK 1.07.

Purcell, S., Neale, B., Todd-Brown, K., Thomas, L., Ferreira, M. A., Bender, D., Maller, J., et al. 2007. PLINK: a tool set for whole-genome association and population-based linkage analyses. The American Journal of Human Genetics, 81: 559-575.

Quincoces, I. 2002. Crecimiento y reproducción de las especies" Lophius budegassa" Spinola 1807 y" Lophius piscatorius" Linneo 1758, del Golfo de Vizcaya., p. 258. Departamento de Zoología y Dinámica Celular Animal, Universidad del País Vasco (EHU/UPV), Spain.

Quincoces, I., Santurtún, M., and Lucio, P. 1998. Biological aspects of white anglerfish (Lophius piscatorius) in the Bay of Biscay (ICES Division VIIla, b, d) in 1996-1997. ICES CM.

Relini, G. 1999. Synthesis of the knowledge on bottom fishery resources in Central Mediterranean (Italy and Corsica). Biol Mar Medit, 6: 276-291. 
Rodríguez-Ezpeleta, N., Bradbury, I. R., Mendibil, I., Álvarez, P., Cotano, U., and Irigoien, X. 2016. Population structure of Atlantic mackerel inferred from RAD-seq-derived SNP markers: effects of sequence clustering parameters and hierarchical SNP selection. Molecular ecology resources, 16: 991-1001.

Rodríguez-Ezpeleta, N., Díaz-Arce, N., Walter lii, J. F., Richardson, D. E., Rooker, J. R., Nøttestad, L., Hanke, A. R., et al. 2019. Determining natal origin for improved management of Atlantic bluefin tuna. Frontiers in Ecology and the Environment, 17: 439-444.

Rousset, F. 2014. Genepop 4.3 for Windows/Linux/Mac OS X. This documentation: July, 8: 2014. Schwenke, P. 2013. History and extent of introgressive hybridization in Puget Sound rockfishes (Sebastes auriculatus, S. caurinus, and S. maliger).

Seehausen, O. 2006. Conservation: losing biodiversity by reverse speciation. Current Biology, 16: R334-R337.

Sevilla, R. G., Diez, A., NorÉN, M., Mouchel, O., JÉRÔMe, M., Verrez-Bagnis, V., Van Pelt, H., et al. 2007. Primers and polymerase chain reaction conditions for DNA barcoding teleost fish based on the mitochondrial cytochrome $b$ and nuclear rhodopsin genes. Molecular Ecology Notes, 7: 730-734.

Stephenson, R. L. 2002. Stock structure and management structure: an ongoing challenge for ICES. ICES marine science symposia, 215: 305-314.

Stronen, A. V., and Paquet, P. C. 2013. Perspectives on the conservation of wild hybrids. Biological Conservation, 167: 390-395.

Team, R. C. 2018. R: A language and environment for statistical computing. R Foundation for Statistical Computing, Vienna, Austria. 2012. URL http://www. R-project. org.

Ungaro, N., Marano, G., Auteri, R., Voliani, A., Massutí, E., García-Rodríguez, M., and Osmani, K. 2002. Distribution, abundance and biological features of anglerfish (Lophius piscatoirus and Lophhius budegassa)(Osteichthyes: Lphiiformes) in the Mediterranean Sea. Scientia Marina, 66: 55-63.

Verheyen, E., Salzburger, W., Snoeks, J., and Meyer, A. 2003. Origin of the superflock of cichlid fishes from Lake Victoria, East Africa. Science, 300: 325-329.

Yaakub, S. M., Bellwood, D. R., van Herwerden, L., and Walsh, F. M. 2006. Hybridization in coral reef fishes: introgression and bi-directional gene exchange in Thalassoma (family Labridae). Molecular Phylogenetics and Evolution, 40: 84-100. 


\section{Supplementary Tables}

Table S1. Samples used for this study with collection data (survey, responsible institute, date, location), biological variables measured (morphological identification, depth in meters, length in $\mathrm{cm}$, weight in $\mathrm{g}$, sex and maturity) and molecular analysis information (used for RAD-seq or not, replicate or not, genetic identification and hybrid class).

[excel file available upon request]

Table S2. Number of individuals and SNPs including in the catalog and remaining after each filtering steps for each dataset (All: all individuals included; L. pis: only those individuals genetically identified as L. piscatorius; L. pis without MED: L. pis dataset without Mediterranean Sea individuals).

\begin{tabular}{|c|c|c|c|c|c|c|c|c|}
\hline & \multicolumn{4}{|c|}{ All } & \multirow{2}{*}{\multicolumn{2}{|c|}{$\begin{array}{c}\text { L. pis } \\
\text { de novo }\end{array}$}} & \multirow{2}{*}{\multicolumn{2}{|c|}{$\begin{array}{c}\text { L. pis without MEL } \\
\text { de novo }\end{array}$}} \\
\hline & \multicolumn{2}{|c|}{ de novo } & \multicolumn{2}{|c|}{ Ref. mapped } & & & & \\
\hline & Inds & Tags/SNPs & Inds & Tags/SNPs & Inds & Tags/SNPs & Inds & Tags/SNPs \\
\hline Catalog & 327 & 25892 & 327 & 35561 & 241 & 23301 & 235 & 23095 \\
\hline Genotyping rate & 323 & 24346 & 327 & 31545 & 238 & 21705 & 232 & 21579 \\
\hline MAF & 323 & 16712 & 327 & 23126 & 238 & 6233 & 232 & 6246 \\
\hline
\end{tabular}




\section{Supplementary Figures}

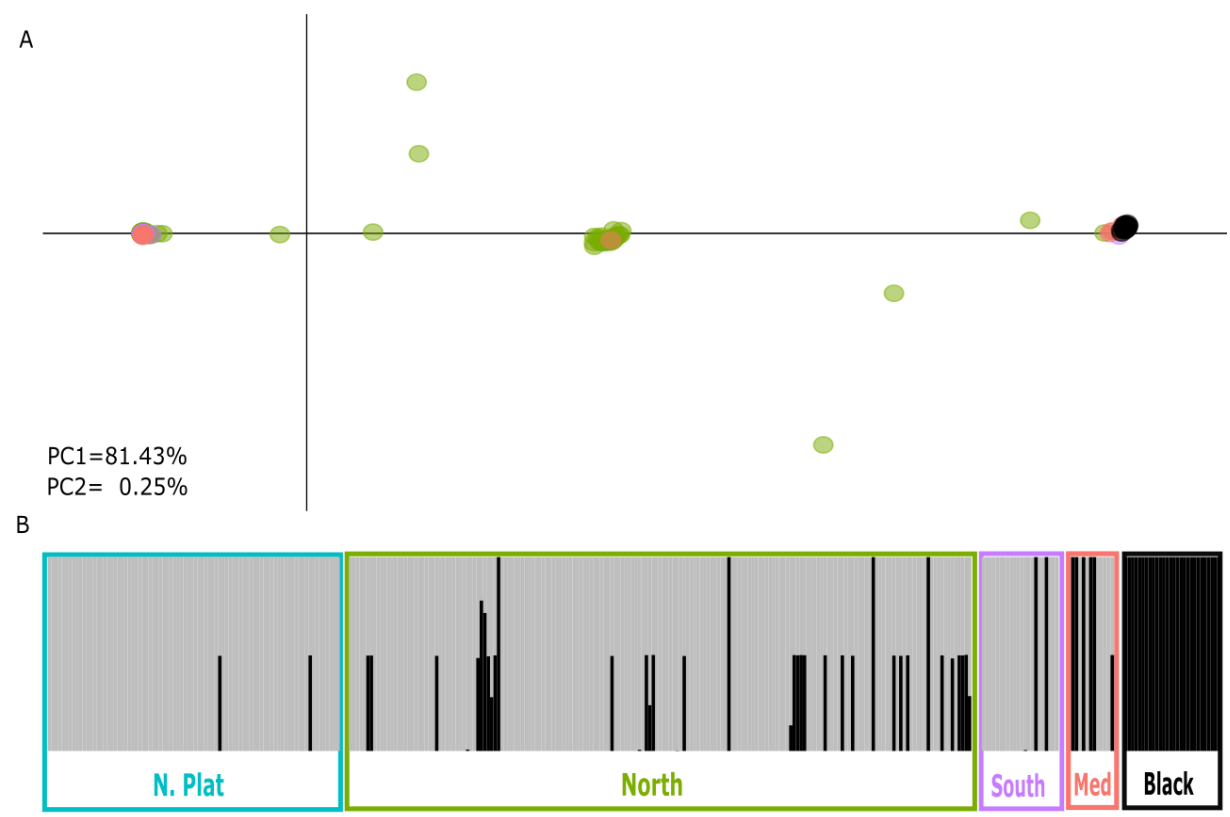

Figure S1. A. Principal Component Analysis (PCA) where main differentiated groups are circled and number of individuals per group for each stock ( $L$. piscatorius) and for $L$. budegassa are indicated. B. Individual ancestry proportions estimated by ADMIXTURE when assuming two ancestral populations. These results are derived from the reference mapped catalog.

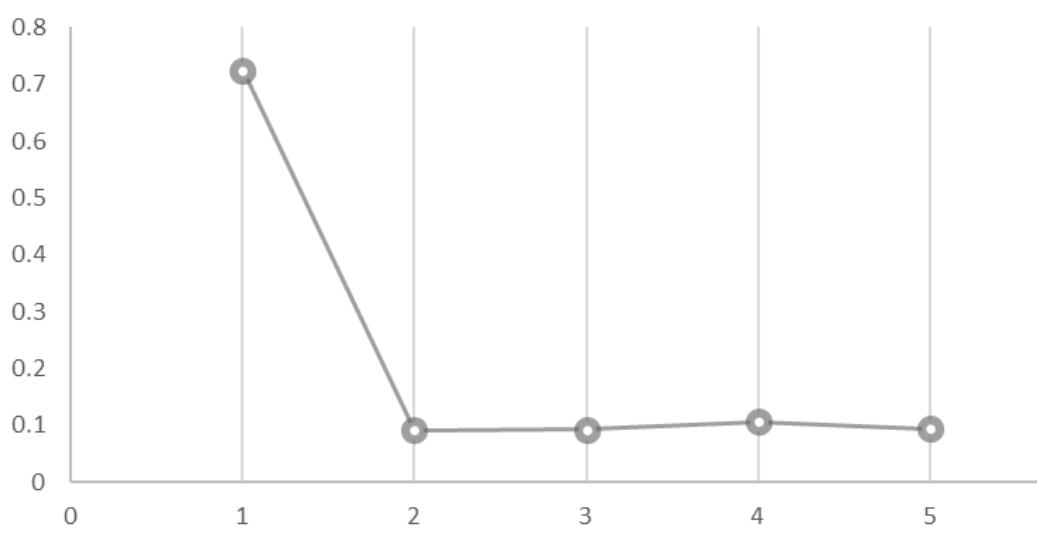

Figure S2. Associated error ( $y$ axis) for each assumed value of $K$ ( $x$ axis) following the crossvalidation method described in the ADMIXTURE manual for the de novo mapped dataset. Cross-validation method described in the ADMIXTURE manual suggests that the most likely number of ancestral populations $(K)$ associated with the lowest error rate is 2. 